\title{
THE INFLUENCE OF CUTTING CONDITIONS ON THE SELECTED PARAMETERS OF THE SURFACE INTEGRITY
}

\author{
Robert ČeP ${ }^{a, *}$, ŠÁrka Malotová $a$, JiŘí LichovníK ${ }^{a}$, Michal Hatala $^{b}$, \\ STANISLAW LEGUTKO ${ }^{c}$
}

${ }^{a} V \check{S} B$ - Technical University of Ostrava, 17. listopadu 15/2172, Ostrava, Czech Republic

${ }^{b}$ Technical University in Košice with the seat in Prešov, Bayerova 1, Prešov, Slovakia

c Poznan University of Technology, 5 M. Sklodowska-Curie Square, 60-965, Poznan, Poland

* corresponding author: robert.cep@vsb.cz

\begin{abstract}
The article deals with an investigation of residual stress in machined surface under conditions of high-feed milling and determination of the influence of machining conditions on the size and types of stress resulting from cutting into the machined surface. As a testing material, the hardened tool steel W. Nr. 1.2343 (CSN 19552) was used. For the realization of the experimental activity, a high-feed milling head was used with exchangeable cutting inserts marked H600 WXCU 070515T. All surfaces were machined under different cutting conditions $\left(200,300,350,400\right.$ and $500 \mathrm{~m} \mathrm{~min}^{-1} \mathrm{cutting}^{-}$ speed) in regard to the recommended parameters and machine tool options. The evaluated residual stress was measured in the depth of $8 \mu \mathrm{m}$ under the surface with the device PROTO iXRD working on the principle of the X-Ray diffraction. Monitoring was carried out using an analysis of occurrence of tensile or compressive residual stress, and from these results, a possible dependence of the residual stress on the cutting conditions during milling process was determined.
\end{abstract}

KEYWORDS: residual stress; milling; machining; X-ray diffraction; surface integrity.

\section{INTRODUCTION}

Worldwide industrial production deals with the manufacturing of airplanes, the energy sector, construction, machines, tooling, cutting, and the quality and final properties of manufactured components. The progressive technologies of machining with high speeds must be the priority of all manufacturing. During machining, in this case, mechanical and thermal loading and final surfaces are exposed to changes, which influence the surface and subsurface layers [1 1 ]. These changes can be classified as the residual stress. The presence of stress in machined surfaces is related to the mechanical loading or the phase transformation. During machining, the residual stress is generated after plastic deformation during the chip forming. A thermal treatment or other processes can change the size and type of residual stress [4].

The residual stress is an important parameter of surface integrity. An investigation can predict the future behaviour of formed surfaces. Several authors (e.g. R.M'Saoubi [7]) deal with the surface integrity and relationship between geometrical and physical properties such as the residual stress. As mentioned above, during chip forming, the change of tension field in material occurs. For that reason, many authors [810. also deal with the influence of cutting parameters on selected parameters of surface integrity.

As authors Frederick Gunnberg et al. 11] describe in the paper "The influence of cutting conditions on residual stress and surface topography", stress can be compressive $(-)$ or tensile $(+)$. Compressive stress

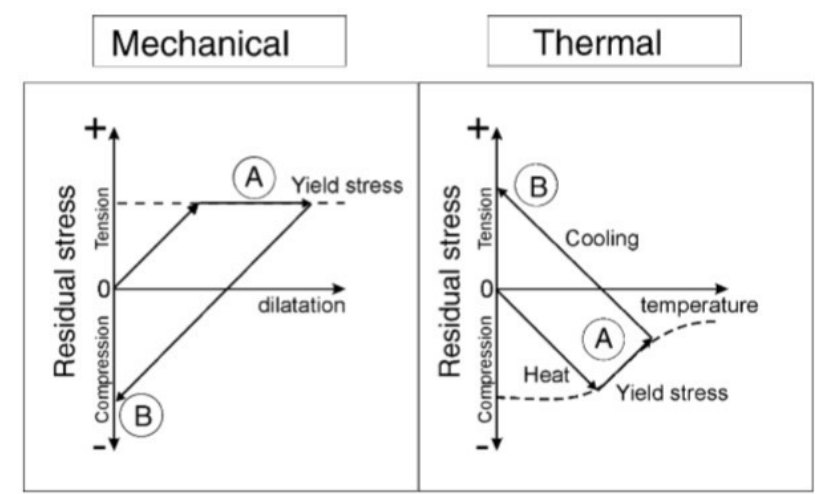

FiguRE 1. Mechanism of the residual stress [11.

is generally useful, because it tends to increase fatigue strength and restricts a spreading of cracks and increases corrosion resistance. Tensile stress is dangerous for components, and it has the opposite impact on the above mentioned material properties. The mechanisms of creation of the residual stress are explained in Figure 1. During the chip forming, tensile stress occurs (A), which may be explained by the plastic deformation into the surface layer and elastic deformation into the subsurface layer. When the machining process is completed, a balance in the microstructure is achieved. Compressive stress is caused from dilatation. (B). The mechanism of residual stress due to heat (Figure 1 right) is caused by the amount of the heat in the cutting zone, which extends into surface layer and creates compressive stress (A). After 


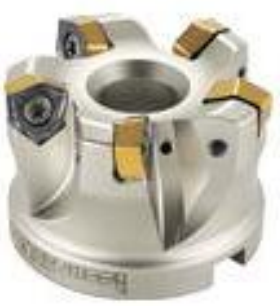

\begin{tabular}{cc}
\hline$v_{c}\left[\mathrm{~m} \mathrm{~min}^{-1}\right]$ & $f_{z}[\mathrm{~mm}]$ \\
\hline 200 & 0.6 \\
& 0.7 \\
& 0.9 \\
\hline 300 & 0.6 \\
& 0.7 \\
& 0.8 \\
& 0.9 \\
\hline 350 & 0.6 \\
& 0.7 \\
& 0.8 \\
& 0.9 \\
\hline 400 & 0.6 \\
& 0.8 \\
\hline 500 & 0.6 \\
\hline
\end{tabular}

TABle 1. Cutting parameters.

the cooling process occurs, the contraction causes the change of the stress. (B). For this reason, it is also important to know the temperature of the cutting wedge, because this temperature will reduce the tensile stress induced into the surface.

There are several methods for the investigation of residual stress with one main classification: destructive or non-destructive. These methods are not only expensive but also time-consuming and they require a broad knowledge of residual stress. A frequently used method is the X-Ray diffraction. Its principle of measurement is a positioning of the sample under the measuring head, when the collimator must be in position perpendicular to the measuring surface [12]. When the focus is set at a right height, the X-Ray beam radiation penetrates into the material, which bounces back. The measuring head leans in a ratio of $-30^{\circ}$ and $+30^{\circ}$ and the measurement is realized step by step into an approximately $8 \mu \mathrm{m}$ depth. The data are processed, and they can be used for the determination of dependences.

\section{SET UP OF THE EXPERIMENT}

The aim of the experiment was focused on the research and distribution of residual stress under the conditions of high-feed milling. Used samples consisting of hardened material Wr. N. 1.2343 (ČSN 19552)

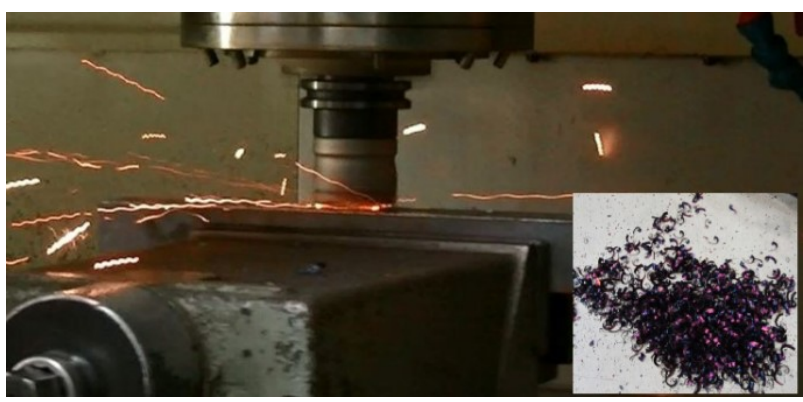

Figure 3. Chip forming.

$42 \pm 2$ HRc were used. The dimensions of samples were $40 \times 40 \times 330 \mathrm{~mm}$. The reason for this choice of material was its repeatability for the form production or shearing tools, and thus it is important to know the state and future behaviour of this material after the manufacturing. This steel is characterized by good hardness, high heat-strength, and very good resistance against creating of cracks. The sample set was machined under the cutting conditions recommended by producer ISCAR. The whole experiment was carried out using the 3 -axis milling centre HURCO WMX 30T, dry machining.

The milling process requires a holding toughness and an increased durability of exchangeable cutting inserts. Therefore, five-teeth milling head ISCAR FF FWX D050-22-07 was used. The head was fit with the inserts H600 WXCU 070515T made from the material IC810. These inserts contain a very fine-grained structure with a high wear resistance. The inserts had a PVD coating on their base, AlTiN+TiN. It is nitride titanium and it prevents a chip jamming at the cutting edge point, and nitride titanium and additives improve the properties and decrease the fracture toughness of the cutting edge. The producer of these cutting tools offers a width ratio of cutting parameters. In regard to the influence of cutting conditions on the milling process, following conditions were selected (Table 1). The depth of the cut was set to $1 \mathrm{~mm}$. The residual stress was measured in machined surfaces. A non-destructive method based on the X-Ray diffraction was used. The stress was measured in the middle part of every sample into approximately $8 \mu \mathrm{m}$ of depth. The values were processed with PROTO iXRD software and are described in the next section. 


\section{Results}

A characteristic feature for machining hard material is the creation of short comma chips, typically of a purple colour. During the process of machining, sparks and chips are generated, which are clearly visible. (Figure 3) Each sample was machined on four surfaces and the results were statistically processed. The stress always had a positive character - tensile stress.

Figure 4 shows an example of the stress distribution for a selected sample. International standard ČSN EN 15305 deals with non-destructive methods. Individual atoms are not grouped around the curve and do not tend to counteract crack propagation in the material structure. This is a hallmark of tensile stress. Shape of the parabola characterizes the accuracy of the measurement - the deviation $\pm 19.7 \mathrm{MPa}$ is about $28 \%$ of the stress. The direction of axis of the parabola describes the type of the stress. With a rising axis of the parabola, the presence of the tensile stress is confirmed.

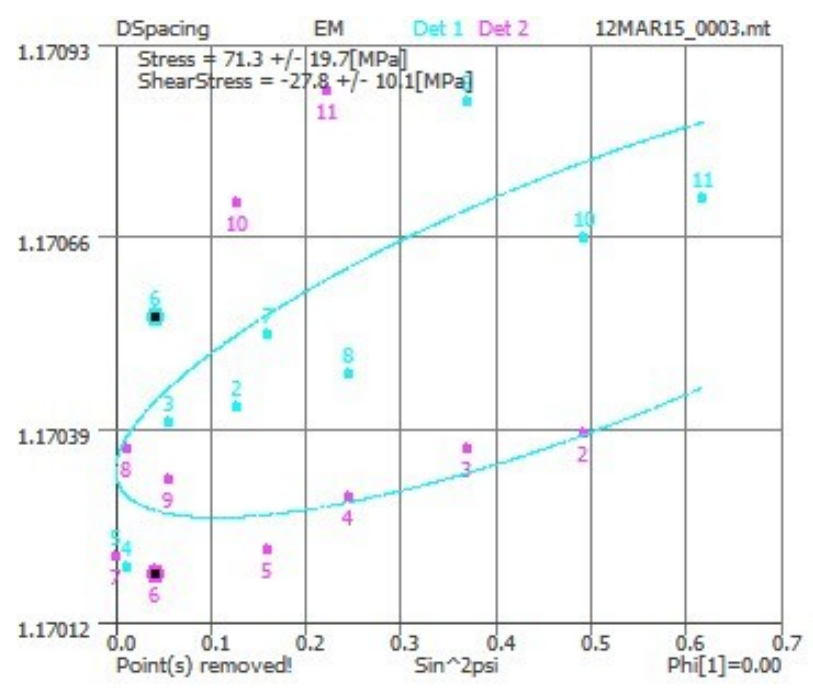

FiguRE 4. Graphic output of residual stress.

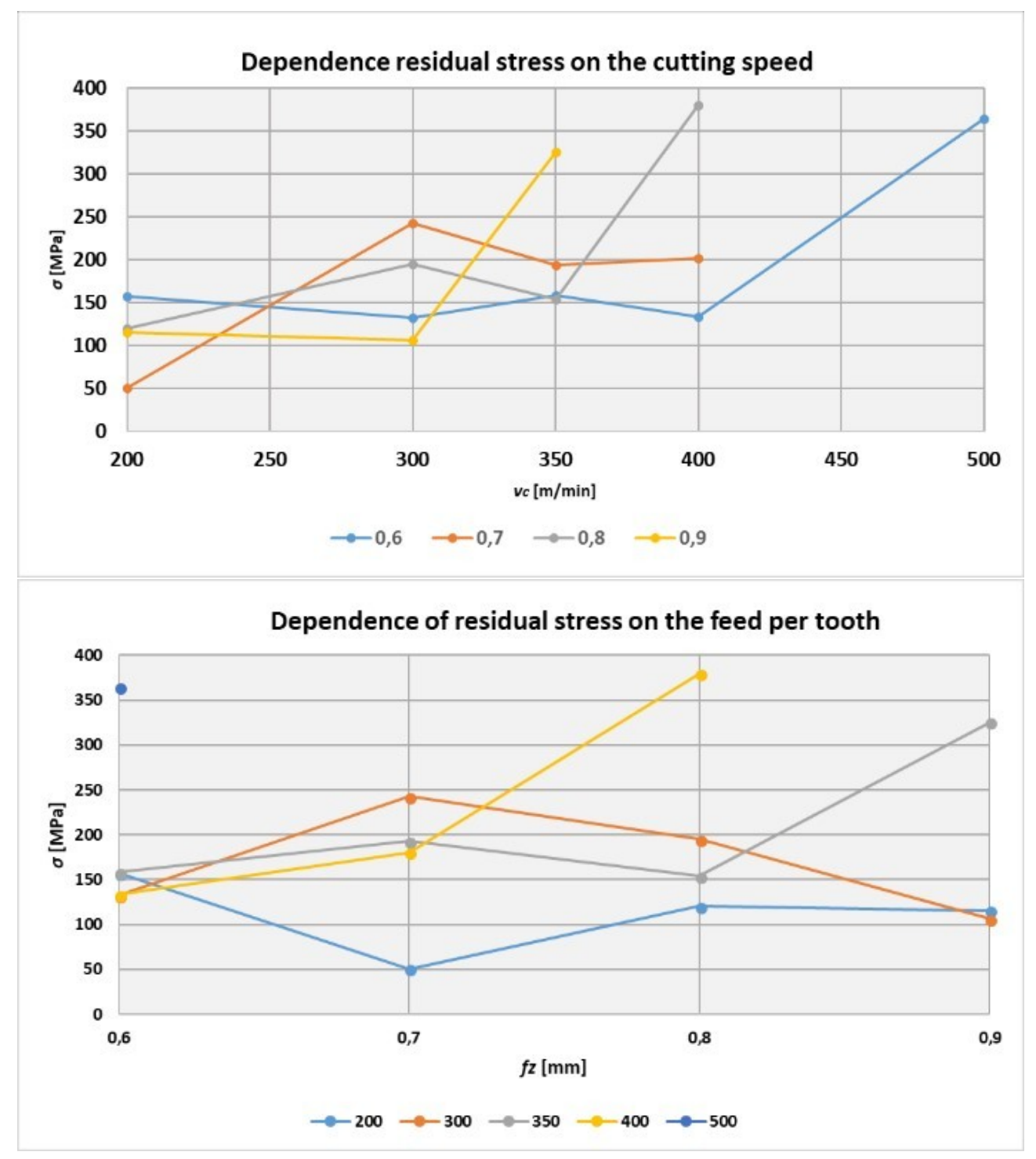

Figure 5. Dependence of residual stress on (left) cutting speed and (right) feeds per tooth. 


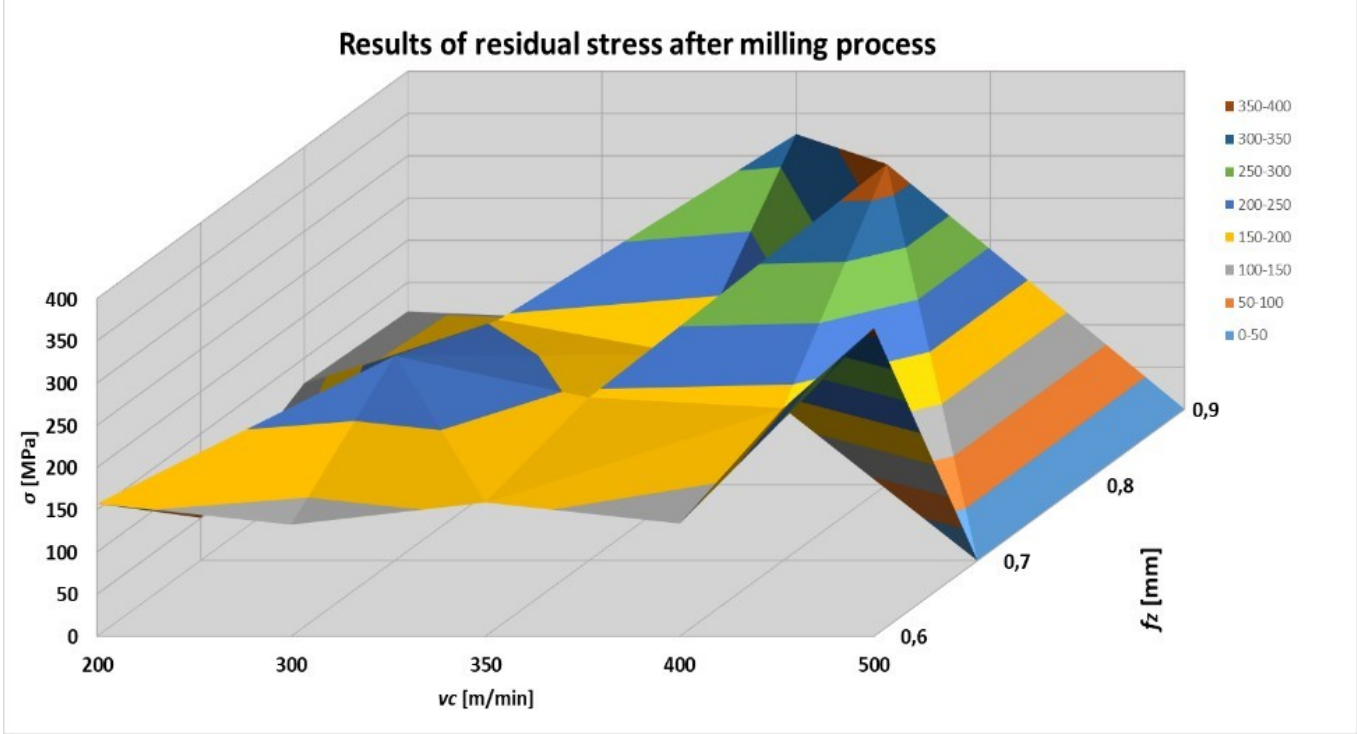

Figure 6. Results of residual stress.

If we consider the potential dependence of the stress on the cutting speed at a constant feed per tooth, no dependence was detected. Figure 5 top illustrates all variants of feeds and the highest stress value was reflected predominantly at the highest chosen cutting speed. However, results could not confirm that increasing cutting speed also increases the stress value. Minor fluctuations could be due to structural changes in the material.

Furthermore, we focused on the results of the stress with a dependence on the increasing feed per tooth and a constant cutting speed. (Figure 5 bottom) Even here, the results didn't confirm the direct dependence between the stress and feed. Initially, the values grew, however, only slight fluctuations followed. For both cases of the dependence, the tensile stress had a significant influence on the thermal effect during the cutting process. As mentioned earlier in the introduction, the stress is predominantly compressive in the surface, and with a cooling process, it converts into positive values - tensile stress. For experimental purposes, the stress was also measured in the non-machined sample. Despite the fact that the values were small, the stress was still tensile. The only finding that can really be confirmed is that the stress occurs in the material even without mechanical loading from machining. Another finding was that the external force changes the size or type of the stress. Figure 6 shows a three-dimensional map of the results.

The residual stress in the surface did not confirm its dependence on the cutting parameters. Therefore, another parameter of the surface integrity, surface roughness, was evaluated within this experiment. The roughness was evaluated on the basis of CSN EN ISO $4287 / 88$ using the device SurfTest SJ 210. The assumption was that with an increasing feed per tooth at a constant cutting speed, the surface roughness ( $\mathrm{Ra}$ value) will increase. That was confirmed. Worsened surface quality was monitored at higher machining parameters, acompanied by significant tool traces.

\section{Conclusion}

The residual stress was evaluated in relation to the selected machined material, technology, and the cutting conditions. For this experiment, we used a hardened tool steel for machining by high-feed milling technology. The evaluation and measurement of residual stress was carried out with the use of a non-destructive X-Ray method.

The results didn't confirm any dependence of the residual stress on an increasing cutting speed with a constant feed per tooth. Each combination of conditions evinced a presence of tensile stress, which was caused during the cooling process. Tensile stress can have an impact on sped-up corrosion, crack propagation in the material structure and lowering the fatigue strength of the material. The stress has a wide range of values. The stress with the highest value was measured in the conditions of the highest value of cutting speed or feed per tooth. There, the stress was up to three times higher.

From the view point of the surface roughness, increasing values of machining conditions result in a poor surface quality with significant tool tracks. With the increasing feed per tooth and a constant cutting speed, the roughness increased.

We can observe that, generally, a machining process has an impact on a tensile and compressive stress and an increase of residual stress into the material. In conclusion, cutting conditions have no effect on residual stress and no dependence, with respect to the residual stress, has been confirmed. If there is an interest for further research of dependencies, the research could evaluate the residual stress in dependence to the measurement of the surface depth and the temperature at the cutting point. 


\section{ACKNOWLEDGEMENTS}

This paper has been supported from Funds of Moravian and Silesian Region within project „The support talented students of doctoral study at VŠB-TU Ostrava“" (reg. no. 04766/2017/RRC).

Article has been done in connection with projects Education system for personal resource of development and research in field of modern trend of surface engineering surface integrity, reg. no. CZ.1.07/2.3.00/20.0037 financed by Structural Founds of Europe Union and from the means of state budget of the Czech Republic and by project Students Grant Competition SP2018/150 and SP2018/136 financed by the Ministry of Education, Youth and Sports and Faculty of Mechanical Engineering VŠB-TUO.

\section{REFERENCES}

[1] TWARDOWSKI, P. et al. Investigation of wear and tool life of coated carbide and cubic boron nitride cutting tools in high speed milling. Advances in Mechanical Engineering. 2015, vol. 7, no. 6. DOI:10.1177/1687814015590216

[2] ČEP, R.; PETRŮ, J.; ZLÁMAL, T. Influence of feed speed on machined surface quality. In: METAL 2013: 22nd International Conference on Metallurgy and Materials. Ostrava: TANGER Ltd., 2013, p. 1033-1038. ISBN 978-80-87294-41-3.

[3] WOJCIECHOWSKI, S.; M. WIACKIEWICZ; G.M. KROLCZYK. Study on metrological relations between instant tool displacements and surface roughness during precise ball end milling. Measurement. 2018, vol. 129, p. 686-694. DOI:10.1016/j.measurement.2018.07.058

[4] GANEV, N.; PALA, Z.; KOLAŘÍK, K. The impact of cutting conditions on residual stresses in the case of plain milling. Materials engineering. 2010, vol. 17, no. 3, p. $9-14$.

[5] PETRŮ, J.; ZLÁMAL, T.; ŠPALEK, F.; ČEP, R. Surface Microhardening Studies on Steels after High Feed Milling. Advances in Science and Technology Research Journal. 2018, vol. 12, no. 2, p. 222-230. DOI: $10.12913 / 22998624 / 91888$
[6] PETRU, J.; ZLAMAL, T; CEP, R; PAGAC, M.; GREPL, M. Influence of strengthening effect on machinability of the welded inconel 625 and of the wrought Inconel 625. In: IMETI 2013 - 6th International Multi-Conference on Engineering and Technological Innovation, Proceedings. Orlando: International Institute of Informatics and Systemics (IIIS), 2013, p. 155-159. ISBN 978-193633892-4.

[7] M'SAOUBI, R. et al. A review of surface integrity in machining and its impact on functional performance and life of machined products. International Journal of Sustainable Manufacturing. 2008, vol. 1, no. 1/2, p. 203-236. DOI:10.1504/IJSM.2008.019234

[8] KROLCZYK, G. M.; LEGUTKO, S. Experimental Analysis by Measurement of Surface Roughness Variations in Turning Process of Duplex Stainless Steel. Metrology and Measurement Systems. 2014, vol. 21, no. 4, p. 686-694. DOI:10.2478/mms-2014-0060

[9] BEIYHI, L. et al. High-speed milling characteristics and the residual stresses control methods analysis of thin-walled parts. Advanced Materials Research. 2011, vol. 223 , p. $456-463$.

[10] KROLCZYK, G. M.; LEGUTKO S.; STOIC A. Influence of cutting parameters and conditions onto surface hardness of Duplex Stainless Steel after turning process. TEHNICKI VJESNIK-TECHNICAL GAZETTE. 2013, vol. 20, no. 6, p. 1077-1080.

[11] GUNNBERG, F.; ESCURSELL, M.; JACOBSON, $\mathrm{M}$. The influence of cutting parameters on residual stresses and surface topography during hard turning of $18 \mathrm{MnCr} 5$ case carburised steel. Journal of Materials Processing Technology. 2006, vol. 174, p. 82-90. DOI:10.1016/j.jmatprotec.2005.02.262

[12] Malotová, Š. et al. Evaluation of Residual Stresses after Irregular Interrupted Machining. Tehnicki vjesnik Technical Gazette. 2018, vol. 25, no. 4, p. 1009-1013. DOI:10.17559/TV-20160615125650 